\title{
Simulation and Experiment Study on Six-degrees-of- freedom Active Micro-vibration Isolation Platform
}

\author{
Gongyu Pan, Dong Li and Yunqiang Xiao \\ School of Automotive and Traffic Engineering, Jiangsu University, Zhenjiang, Jiangsu, China, 212013
}

\begin{abstract}
A six-degrees-of-freedom active micro-vibration isolation control system has been proposed and studied. The system consists of passive air springs and symmetrically placed electro-magnetic actuators. A mathematical model of the microvibration isolation platform is established, and $H_{\infty}$ control algorithm is designed for isolating vibration system. Simulation and experiment is carried out to verify the effectiveness of active micro-vibration control system. The results demonstrate that the proposed micro-vibration control system has good isolation performance.
\end{abstract}

Keywords-active vibration control ; micro-vibration platform; electro-magnetic actuator

\section{INTRODUCTION}

In recent years, with the rapid development of micro manufacturing technology and precision measurement technology, micro vibration control technology has become a very important research topic. Passive vibration isolation technique is often used to achieve this goal. However, due to the natural frequency of the passive vibration isolation device cannot be reduced to very low, it is difficult to effectively isolate the low frequency vibration signal with the traditional passive isolation technology. Active vibration isolation technique is an effective vibration control method, in which external force is used to control the vibration energy. Comparing with the passive vibration isolation, the active vibration isolation technology is much more effective, especially in the low frequency range ${ }^{[1]-[3]}$.

In this paper, a comprehensive vibration isolation system combined the passive vibration isolation and the active vibration isolation technology is proposed and used in a precision isolation platform. The 6 degrees of freedom micro vibration control system consists of air springs as the passive vibration isolation elements and electro-magnetic actuators as the active vibration isolation elements. $H_{\infty}$ control algorithm is designed for the active vibration control system. Simulation analysis and experiment are carried out to verify the vibration effect of the micro vibration system. The results show that the active platform not only has better isolation effect on high frequency disturbance, and very effective in the ultra low frequency of low frequency vibration disturbance.

\section{VIBRATION ISOLATION SYSTEM PLATFORM}

\section{A. Structure Model}

The structure model of micro-vibration isolation platform is shown in figure 1. The micro-vibration isolation platform uses air springs as the passive vibration isolation components, electro-magnetic actuators as the active vibration isolation elements. Through the detection system and control system, a closed-loop active vibration control system is constituted, so as to effectively eliminate the interference of vibration. The system can effectively isolate various frequency vibration passed over by the platform base, even for low frequency vibration that passive vibration isolation system is difficult to eliminate or ultra low frequency interference.

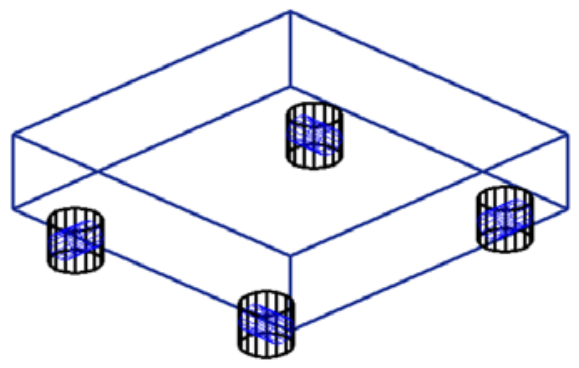

FIGURE I. MICRO-VIBRATION ISOLATION PLATFORM

\section{B. Equation of Motion}

Assuming the table is a rigid body, the equation of motion of the table is as follows.

$$
[M]\{\ddot{x}\}+[C]\{\dot{x}\}+[K]\{x\}=-[M]\{\ddot{z}\}+[H][F]\{u\}
$$

where $\{x\}$ is the relative displacement at the gravitational center of the table $(6 \times 1) ;[M]$ is the mass matrix $(6 \times$ $6) ;[C]$ is the damping matrix $(6 \times 6)) ;[K]$ is the stiffness matrix $(6 \times 6) ;\{\ddot{z}\}$ is the floor acceleration $(6 \times 6) ;[H]$ is the arrangement matrix of actuator $(6 \times 8))$; $[F]$ is the transfer function of control signal to force of actuator $(8 \times$ 8); $\{u\}$ is the control signal to actuator $(8 \times 1)$.

Let us introduce the modal coordinate expression.

$$
\{\mathrm{x}\}=[\varphi]\{\xi\}
$$


$\{\xi\}$ is the modal coordinate of the table corresponding to relative displacement of the table $(k \times 1) ; k$ means the number of modes considered. $[\varphi]$ is the modal matrix $(6 \times k)$.

$$
[\varphi] \mathrm{T}[\mathrm{M}][\varphi]=[\mathrm{I}]=\operatorname{diag}([1, \ldots, 1]) \quad(\mathrm{k} \times \mathrm{k})
$$

$$
[\varphi] \mathrm{T}[\mathrm{C}][\varphi]=\left[\mathrm{C}^{*}\right]=\operatorname{diag}([2 \varsigma 1 \omega 1, \ldots, 2 \varsigma \mathrm{k} \omega \mathrm{k}])(\mathrm{k} \times \mathrm{k})
$$

$$
[\varphi] \mathrm{T}[\mathrm{K}][\varphi]=\left[\mathrm{K}^{*}\right]=\operatorname{diag}([\omega 12, \ldots, \omega \mathrm{k} 2])(\mathrm{k} \times \mathrm{k})
$$

$\omega_{i}$ is the $i$ th modal natural frequency; $\varsigma_{i}$ is the $i$ th modal damping factor.

The equation of motion for modal relative coordinate $\{\xi\}$ becomes as follows.

$$
\begin{gathered}
\{\ddot{\xi}\}+\left[\mathrm{C}^{*}\right]\{\dot{\xi}\}+\left[\mathrm{K}^{*}\right]\{\xi\} \\
=-[\varphi] \mathrm{T}[\mathrm{M}]\{\ddot{z}\}+[\varphi] \mathrm{T}[\mathrm{H}][\mathrm{F}]\{\mathrm{u}\}
\end{gathered}
$$

Here we introduce $\{y\}$, the modal absolute coordinate,

$$
\begin{aligned}
& \{\ddot{y}\}=\{\ddot{\xi}\}+[\varphi] \mathrm{T} \mathrm{[M]}\{\ddot{z}\} \\
& \left\{{ }^{\dot{y}}\right\}=\{\dot{\xi}\}+[\varphi] \mathrm{T}[\mathrm{M}]\{\dot{z}\} \\
& \left\{y^{y}=\{\xi\}+[\varphi] \mathrm{T}[\mathrm{M}]\{z\}\right.
\end{aligned}
$$

The equation of motion for modal absolute coordinate $\{y\}$ becomes as follows.

$$
\begin{aligned}
\{\ddot{y}\}+\left[\mathrm{C}^{*}\right]\left\{\dot{y}^{\dot{y}}\right\}+\left[\mathrm{K}^{*}\right]\left\{{ }^{y}\right\}=\left[\mathrm{C}^{*}\right][\varphi] \mathrm{T}[\mathrm{M}]\{\dot{z}\} \\
+\left[\mathrm{K}^{*}\right][\varphi] \mathrm{T}[\mathrm{M}]\{\mathrm{z}\}+[\varphi] \mathrm{T}[\mathrm{H}][\mathrm{F}]\{\mathrm{u}\}
\end{aligned}
$$

\section{DESIGN OF THE CONTROL SySTEM}

The micro-vibration system is assumed to have six independent degrees of freedom, therefore, the control rule of each degree of freedom can designed respectively. Here the $H_{\infty}$ control algorithm is used in the active micro-vibration system. If the state variable is assumed the following,

$$
x=\left\{x_{i}(t) \quad x_{i}(t)\right\}^{T}
$$

Thus, the formula (1) can be converted into the following equation of state.

$$
\begin{gathered}
\dot{x}=\left[\begin{array}{cc}
0 & 1 \\
-\omega_{i}^{2} & -2 \xi_{i} \omega_{i}
\end{array}\right] x+\left[\begin{array}{ll}
0 & 0 \\
1 & 0
\end{array}\right] w+\left[\begin{array}{l}
0 \\
1
\end{array}\right] u \\
y=\left[\begin{array}{ll}
1 & 0
\end{array}\right] x+\left[\begin{array}{ll}
0 & 1
\end{array}\right] w
\end{gathered}
$$

Here: $u$ is control output, $u=u_{i}(t) ; y$ is measurement output; $w=\left\{\xi_{i}(t) \quad w_{2}\right\}^{T}, w_{2}$ is measurement noise.

If the interference suppression target is expressed as follows:

$$
z=\left[\begin{array}{ll}
1 & 0 \\
0 & 0
\end{array}\right] x+\left[\begin{array}{l}
0 \\
1
\end{array}\right] u
$$

The generalized controlled object will becomes as follows.

$$
x=A x+B_{1} w+B_{2} u
$$

$$
z=C_{1} x+D_{11} w+D_{12} u
$$

$$
y=C_{2} x+D_{21} w+D_{22} u
$$

Here:

$$
\begin{gathered}
A=\left[\begin{array}{cc}
0 & 1 \\
-\omega_{i}^{2} & -2 \xi_{i} \omega_{i}
\end{array}\right] ; B_{1}=\left[\begin{array}{ll}
0 & 0 \\
1 & 0
\end{array}\right] ; B_{2}=\left[\begin{array}{l}
0 \\
1
\end{array}\right] ; \\
C_{1}=\left[\begin{array}{cc}
1 & 0 \\
0 & 0
\end{array}\right] D_{11}=\left[\begin{array}{ll}
0 & 0 \\
0 & 0
\end{array}\right] ; C_{2}=\left[\begin{array}{ll}
1 & 0
\end{array}\right] ; \\
D_{21}=\left[\begin{array}{ll}
0 & 1
\end{array}\right] ; D_{12}=\left[\begin{array}{l}
0 \\
1
\end{array}\right] ; D_{22}=0
\end{gathered}
$$

And the closed loop transfer function matrix will be as follow.

$$
G(s)=\left[\begin{array}{cc}
G_{11}(s) & G_{12}(s) \\
G_{21}(s) & G_{22}(s)
\end{array}\right]=\left[\begin{array}{ccc}
A & B_{1} & B_{2} \\
C_{1} & D_{11} & D_{12} \\
C_{2} & D_{21} & D_{22}
\end{array}\right]
$$




$$
\left[\begin{array}{l}
z \\
y
\end{array}\right]=G(s)\left[\begin{array}{l}
w \\
u
\end{array}\right]=\left[\begin{array}{ll}
G_{11}(s) & G_{12}(s) \\
G_{21}(s) & G_{22}(s)
\end{array}\right]\left[\begin{array}{l}
w \\
u
\end{array}\right]
$$

$$
u=K(s) y
$$

The closed loop transfer function from $\mathrm{z}$ to $\mathrm{w}$ matrix is the following.

$$
G_{z \omega}(s)=G_{11}+G_{12} K\left(I-G_{22} K\right)^{-1} G_{21}
$$

The feedback control law (19) should be designed to make the closed-loop system stable.

$$
\left\|G_{\tau \omega}(s)\right\|_{\infty}<\gamma
$$

Though solving the following two Riccati equations.

$$
A^{T} X_{\infty}+X_{\infty} A+X_{\infty}\left(\gamma^{-2} B_{1} B_{1}^{T}-B_{2} B_{2}^{T}\right) X_{\infty}+C_{1}^{T} C_{1}=0
$$

$$
A Y_{\infty}+Y_{\infty} A^{T}+Y_{\infty}\left(\gamma^{-2} C_{1}^{T} C_{1}-C_{2}^{T} C_{2}\right) Y_{\infty}+B_{1} B_{1}^{T}=0
$$

The output feedback dynamic controller can be obtained.

$$
K(s)=\left[\begin{array}{cc}
\hat{A} & -Z_{\infty} L_{\infty} \\
F_{\infty} & 0
\end{array}\right]
$$

Here:

$$
\begin{gathered}
\hat{A}_{\infty}=A+\gamma^{-2} B_{1} B_{1}^{T} X_{\infty}+B_{2} F_{\infty}+Z_{\infty} L_{\infty} C_{2} \\
F_{\infty}=-B_{2}^{T} X_{\infty} \\
\left.L_{\infty}=-Y_{\infty} C_{2}^{T}\right) \\
Z_{\infty}=\left(I-\gamma^{-2} Y_{\infty} X_{\infty}\right)^{-1}
\end{gathered}
$$

\section{SIMULATION AND EXPERIMENT}

\section{A. Simulation}

The natural frequency of $\mathrm{X}, \mathrm{Y}, \mathrm{Z}$ direction of the microvibration isolating system is designed as $4.0 \mathrm{~Hz}, 4.5 \mathrm{~Hz}$ and $5.0 \mathrm{~Hz}$ respectively. And using Matlab, Control Toolbox and Robust Control Toolbox, the feedback controller K(s) can be got. Figures 2-7 show the transmission function of six-degreesfreedom in the passive and active state. It clearly shows the active state has better isolation performance than passive one.

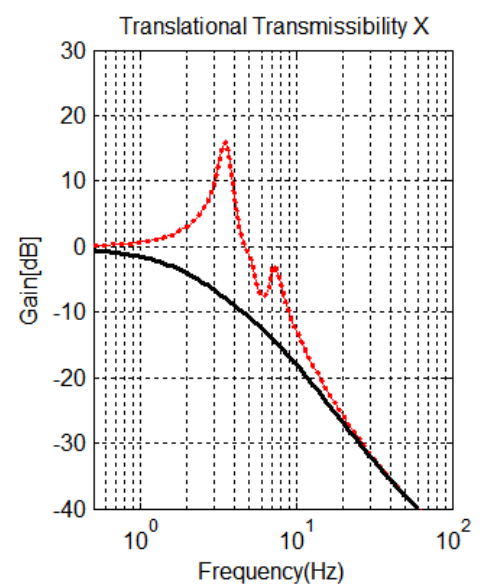

FIGURE II. X DIRECTION'S PASSIVE AND ACTIVE TRANSMISSIBILITY

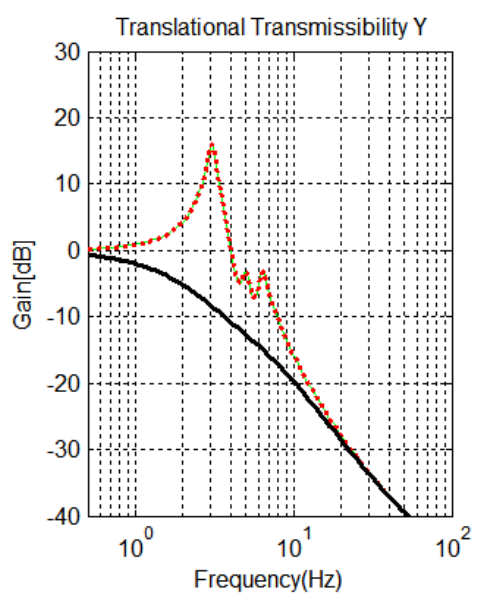

FIGURE III. Y DIRECTION'S PASSIVE AND ACTIVE TRANSMISSIBILITY 


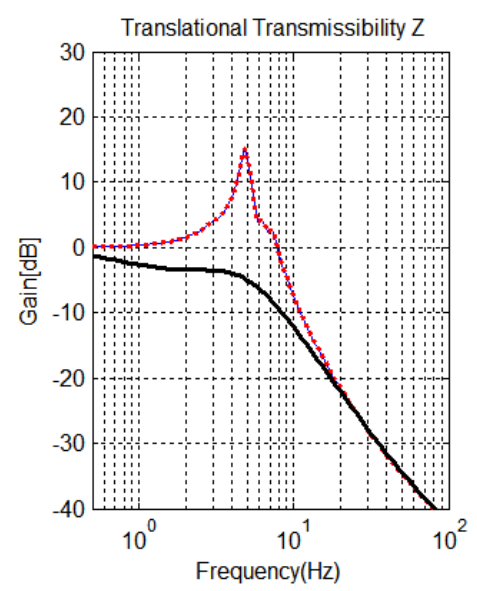

FIGURE IV. Z DIRECTION'S PASSIVE AND ACTIVE TRANSMISSIBILITY

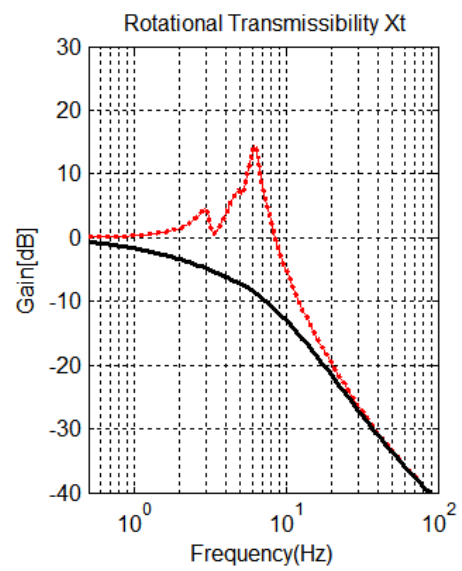

FIGURE V. $\mathrm{X}_{\mathrm{T}}$ DIRECTION PASSIVE AND ACTIVE TRANSMISSIBILITY

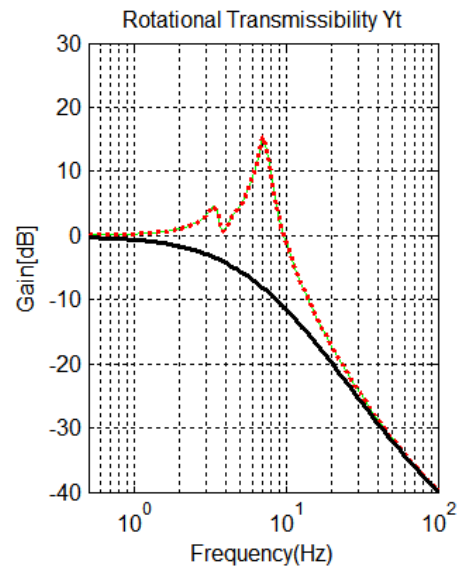

FIGURE VI. Y $Y_{\mathrm{T}}$ DIRECTION PASSIVE AND ACTIVE TRANSMISSIBILITY

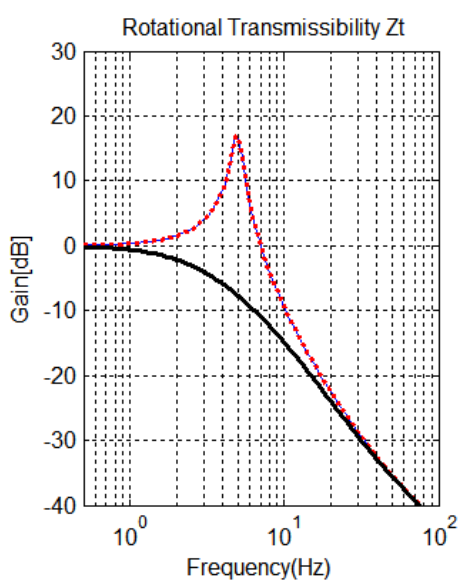

FIGURE VII. $Z_{\mathrm{T}}$ DIRECTION'S PASSIVE AND ACTIVE TRANSMISSIBILITY

\section{B. Experiment}

Figure 8 shows the experimental block diagram of the active vibration control system. Here only the $\mathrm{Z}$ direction vibration performance is confirmed.

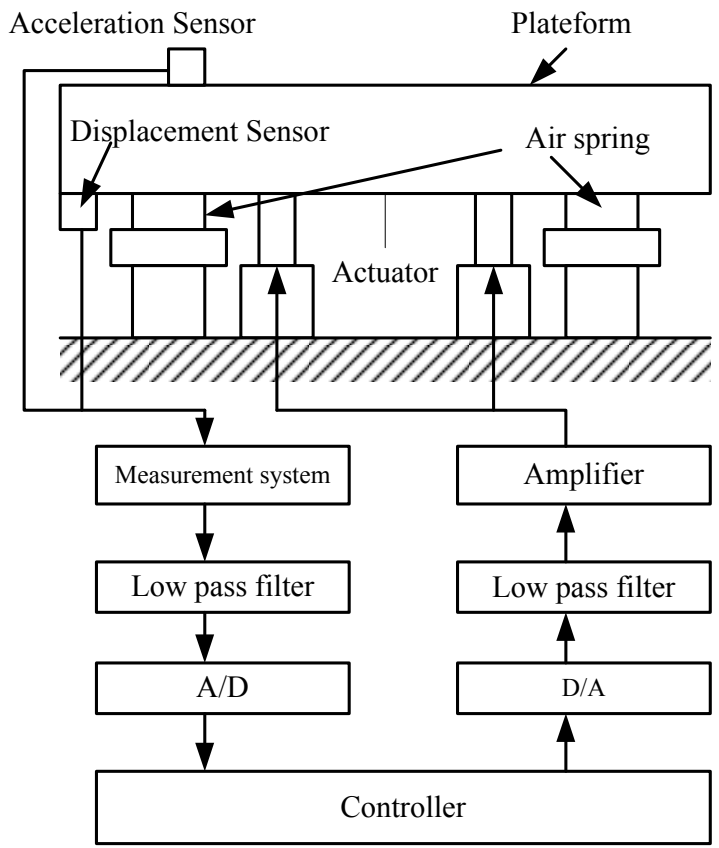

FIGURE VIII. BLOCK DIAGRAM OF THE ACTIVE VIBRATION CONTROL SYSTEM.

Figures 9-10 show the experimental results. The transmission function of $\mathrm{Z}$ direction in the passive state is showed in figure 9 and the transmission function of $Z$ direction in the active state is showed in figure 10.

Comparing the figure 9 with the figure 4 , it is found the simulation is well fit with the experiment. And the figure 10 shows that the ground vibration signal can be effectively isolated with the active control system. 


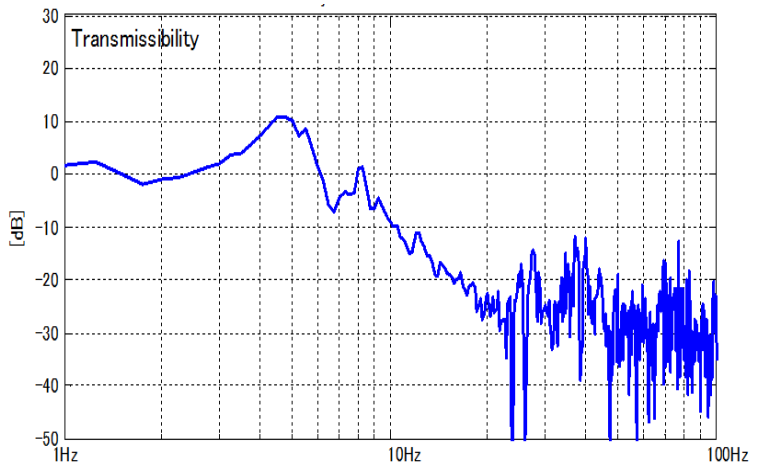

FIGURE IX. TRANSMISSIBILITY OF Z DIRECTION IN THE PASSIVE STATE

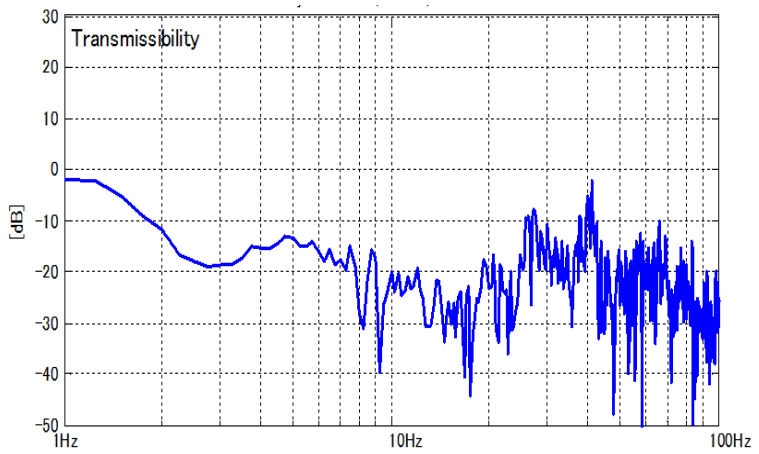

FIGURE X. TRANSMISSIBILITY OF Z DIRECTION IN THE ACTIVE STATE

\section{CONCLUSION}

A comprehensive vibration isolation system combined the air spring passive vibration isolation and the active vibration isolation technology with electro-magnetic actuator is proposed and used in a precision isolation platform. The simulation and experimental show the active isolation system can effectively isolate the ground disturbance in wide frequency range.

\section{ACKNOWLEDGMENT}

This work was supported by the Six Talent Peaks Project of Jiangsu Province under Grant No.2013-ZBZZ-024, the national Natural Foundation of China under Grant No.51375212.

\section{REFERENCES}

[1] Gardonio P, Elliott S J, Pinnington R J. Active isolation of structural vibration on a multiple degree of freedom system, Part I: The dynamics of the system[J]. Journal of Sound and Vibration, 1997, 207 (1): 61-93.

[2] Nakamura Y, Nakayama M, Kura M, Yasuda M, Fujita T. Application of active micro-vibration control system usinga giant magnetostrictive actuator[J]. Intelligent Material Systems and Structures, 2007, 18(11): 1137-1148.

[3] Y. L. Xu and B. Li. Hybrid platform for high-tech equipment protection against earthquake and microvibration $[\mathrm{J}]$. Earthquake Engineering \& Structural Dynamics, 2006, 35: 943-967. 